\title{
Shower heat exchanger: reuse of energy from heated drinking water for $\mathrm{CO}_{2}$ reduction
}

\author{
Z. Deng ${ }^{1,2}$, S. Mol ${ }^{1}$, and J. P. van der Hoek ${ }^{1,2}$ \\ ${ }^{1}$ Waternet, P.O. Box 94370, 1090 GJ Amsterdam, the Netherlands \\ ${ }^{2}$ Delft University of Technology, Department of Water Management, Stevinweg 1, \\ 2628 CN Delft, the Netherlands \\ Correspondence to: Z. Deng (zdeng2014@outlook.com) \\ Received: 13 April 2015 - Published in Drink. Water Eng. Sci. Discuss.: 14 July 2015 \\ Revised: 5 January 2016 - Accepted: 5 January 2016 - Published: 27 January 2016
}

\begin{abstract}
The heating of drinking water in households contributes significantly to the emission of greenhouse gases. As a water utility aiming to operate at a climate neutral level by 2020 , Waternet needs to reduce its

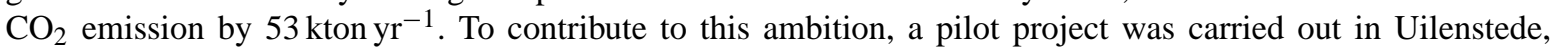
Amstelveen, the Netherlands, to recover the shower heat energy with a shower heat exchanger from Dutch Solar Systems. An experimental setup was built in the Waternet laboratory to evaluate the claimed efficiencies. The energy recovery efficiency observed in the lab was $61-64 \%$ under winter conditions and $57-62 \%$ under summer conditions, while the energy recovery efficiency observed in Uilenstede was 57\% in December 2014. Based on the observations, $4 \%$ of the total energy consumption of households in Amsterdam (electricity and gas) can be recovered with a shower heat exchanger installed in all households in Amsterdam, which also means a 54 kton year $^{-1} \mathrm{CO}_{2}$ emission reduction can be achieved.
\end{abstract}

\section{Introduction}

In the Netherlands, domestic drinking water consumption is 118.9 L per capita per day (Van Thiel, 2014). Drinking water used for showering, bathing, washing dishes by machine, and washing clothes by machine, is heated and contributes to $59 \%$ of domestic drinking water consumption. Drinking water is also warmed by room temperature during nonconsumption periods (i.e., stagnant water in pipes inside the building or in toilets). A substantial amount of thermal energy is added to drinking water after the water has been used. According to Hofman et al. (2011), this heated drinking water exits the house at an average temperature of $27^{\circ} \mathrm{C}$, and it contributes to $40 \%$ of the total heat loss of a modern house (through water by wastewater discharge or through the air by ventilation), which is equivalent to $450 \mathrm{~kg} \mathrm{CO}_{2} \mathrm{yr}^{-1}$ (van der Hoek, 2012a).

Waternet, the water utility of Amsterdam and its surrounding area, has the ambition to operate climate neutral by 2020 (Van der Hoek, 2012a). This ambition is driven by the policy targets of the City of Amsterdam, which has aspired to be a climate neutral municipal organization since 2015 with respect to municipal services, buildings, and activities. For the whole city of Amsterdam, a $40 \%$ reduction in 2025 and a $75 \%$ reduction in 2040 in greenhouse gas emissions, compared to the 1990 emissions (City of Amsterdam, 2009), should be achieved. For Waternet, a climate neutral operation necessitates a reduction of greenhouse gas emissions of $53 \mathrm{kton} \mathrm{CO}_{2} \mathrm{yr}^{-1}$ (Van der Hoek, 2012b). For the City of Amsterdam, a $75 \%$ reduction in greenhouse gas emissions

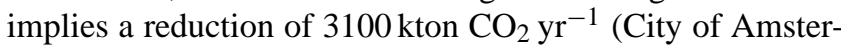
dam, 2009).

The importance of reducing greenhouse gas emissions is even more stressed when the IPCC's (Intergovernmental Panel on Climate Change) Fifth Assessment Report is taken into account (IPCC, 2013). One of the conclusions is that continued emissions of greenhouse gases will cause further warming and changes in all components of the climate system. Limiting climate change will require substantial and sustained reductions of greenhouse gas emissions. 
For Waternet, first calculations revealed that a

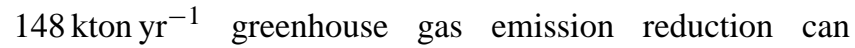
be reached through energy recovery from the water cycle in

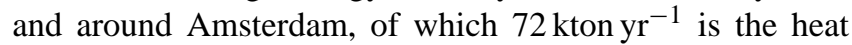
from wastewater (van der Hoek, 2012a). Thermal energy recovery from heated drinking water is a promising way to reach climate neutrality by 2020 .

Taking into account the three main components for heat recovery (a heat source, a heat exchanger, and a consumption point), suitable conditions have to be found to optimize its feasibility. Compared to the mixed heated water from households, shower water seems more attractive due to the fact that it has a high volume (about $50 \mathrm{~L} \mathrm{day}^{-1}$ ) and a high temperature (about $35^{\circ} \mathrm{C}$ ). Furthermore, the consumption and recovery are simultaneous in time and location; thus, no storage system is required, and no extra losses take place during a short distance of heat delivery.

A shower heat exchanger is specially designed for recovering thermal energy from used shower water. It can be installed under a shower tray to transfer the heat from shower water to cold drinking water. As the drinking water has been preheated, total energy consumption to heat the water can be reduced.

In 2010, Liu et al. (2010) proposed a solar heat pump system to provide hot water for large-scale public shower facilities, from both thermal energy in used shower water and solar energy (Liu et al., 2010). Although this system has not yet been implemented, it has been estimated to be practically applicable. The system costs less than EUR 4000, and it would consume $88.9 \%$ less electricity than the original electric boiler (which has an annual electricity consumption of $500361 \mathrm{kWh}$ ). Moreover, its $\mathrm{CO}_{2}$ emission would be only 76.9 ton $\mathrm{yr}^{-1}$. Another study done by Wong et al. (2010) also showed the high energy saving potential of a shower heat exchanger (Wong et al., 2010). They tested the efficiency of a horizontal shower heat exchanger, and estimated that an annual energy saving of 4-15\% can be achieved in a 40 floor (20 apartments per floor) high-rise residential building.

There are many commercial shower heat exchanger types on the market, but not many studies have been done to validate their recovery efficiency, or estimate their potential in energy saving and $\mathrm{CO}_{2}$ reduction.

The company Dutch Solar Systems (DSS) claims their shower heat exchanger has an energy recovery efficiency of $47 \%$ (horizontal version) to $62 \%$ (vertical version), based on a given flow rate (Dutch Solar Systems, 2015). This means that about half of the heat in the shower water can be recovered to reduce energy (i.e., electricity, gas) consumption.

To validate the energy recovery efficiency of the DSS shower heat exchanger in practice, a pilot project was constructed in Campus Uilenstede, a housing estate for students in Amstelveen, in September 2014. An experimental setup was built in the Waternet laboratory with the same configuration as in the student apartments (vertical shower heat ex- changer), in order to further validate the recovery efficiency of the shower heat exchanger under different conditions.

The energy recovery efficiency was studied regarding four main factors:

- flow rate

- duration of the shower

- time interval between two showers

- shower temperature and incoming water temperature.

The annual energy saving potential, and the economic payback time of the shower heat exchangers were calculated, and compared with the DSS documents and former estimations.

In addition, the contribution of shower heat exchangers to the greenhouse gas emission reduction target of Amsterdam was calculated, assuming that all households will be equipped with a shower heat exchanger.

\section{Materials and methods}

\subsection{Installations and configurations}

Considering the cost and efficiency, the DSS shower heat exchangers were chosen and installed in the Uilenstede pilot project, and therefore this specific shower heat exchanger was tested.

\subsubsection{Project Uilenstede}

In Uilenstede Amstelveen, 100 shower heat exchangers were installed in single-student apartments; 10 apartments were monitored: two reference apartments without a shower heat exchanger, two apartments with the horizontal version, and six with the vertical version. The vertical shower heat exchanger (62\% recovery efficiency) was preferred for the pilot project, but it could not be installed on the ground floor. Therefore, two horizontal exchangers were installed. These rooms were monitored with two flow meters (Kamstrup Multical ${ }^{\circledR} 62$ ) and two temperature sensors (SIEMENS QAD2012). The locations of these rooms are shown in Fig. 1. The distance between the heater and the thermostatic shower valve is $1.5 \mathrm{~m}$; the distance between the shower drain and the shower heat exchanger is $0.3-0.5 \mathrm{~m}$. The configuration of the setup in each room is illustrated in Fig. 2.

In Fig. 2, the purple line represents the cold water flow, which partially goes to the taps (in bathroom and kitchen) and partially goes to the shower heat exchanger and heater. Its flow and temperature are measured by the two sensors - F total and $T$ cold. The blue line represents the preheated water, which feeds both the thermostatic valve and the heater. Two sensors, $T$ preheated and $F$ shower, are measuring its temperature and flow, respectively. The red line represents the water heated by the heater and leads to all hot waterconsuming points. 

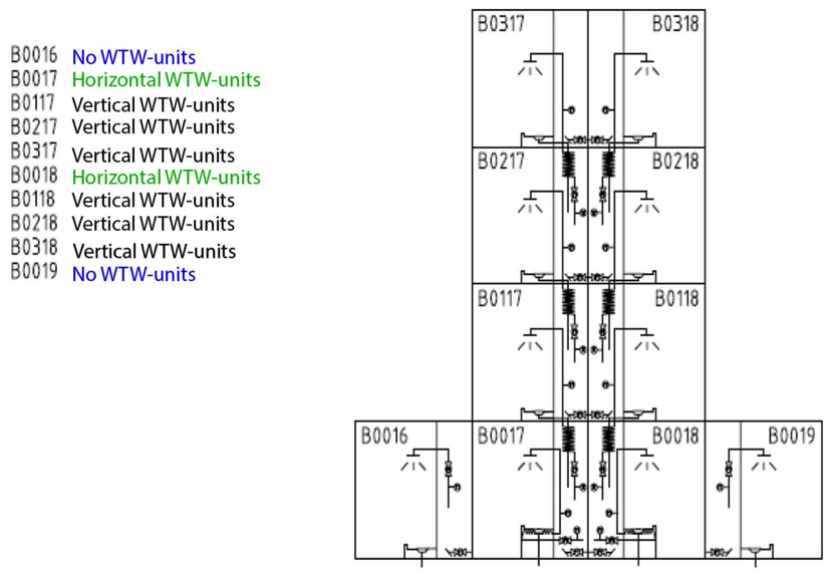

Figure 1. Student apartments monitored.

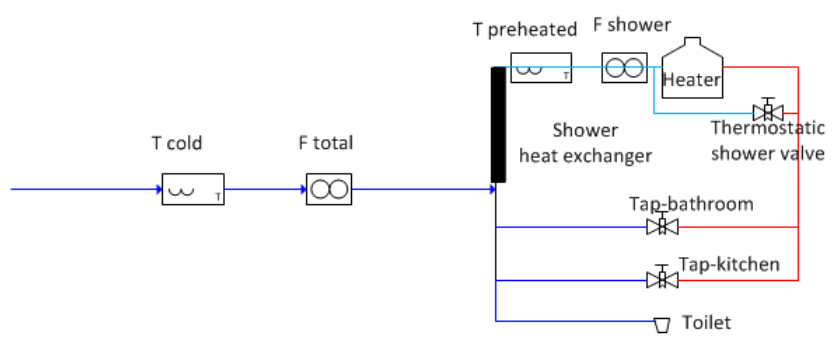

Figure 2. Project setup diagram ( $\mathrm{F}$ is flow meter, $\mathrm{T}$ is temperature sensor).

These four sensors start to collect data whenever there is water consumption in the room; thus, all showers taken were recorded and stored by a SEMAPHORE T-BOX (an open station for remote control, equipped with data logger, alarm transmitter, and server), and then the recorded data were transported to the Waternet database via the Internet. The temperature of the shower water near the drain was measured manually. In Uilenstede, the conditions (flow rate, temperature) of showers taken by the occupants (students) were not controlled, but only monitored from September to December 2014. The records were used to calculate the practical energy recovery efficiency of the shower heat exchanger. The temperature of the shower water in the student's rooms was $34.5-37.5^{\circ} \mathrm{C}$, the cold water temperature was $12.5-14.5^{\circ} \mathrm{C}$ (was $20^{\circ} \mathrm{C}$ in a few days in September), the pre-heated water temperature was $26.0-28.0^{\circ} \mathrm{C}$, and the flow rate was $5.8-$ 6.4 $\mathrm{L} \mathrm{min}^{-1}$.

\subsubsection{Laboratory}

Due to the lack of data from the project site, a laboratory setup was built to mimic the performance of the shower heat exchanger in Uilenstede. In a more controlled environment, the efficiency of the shower heat exchanger could be evaluated, and, furthermore, the relevant factors could be investigated.

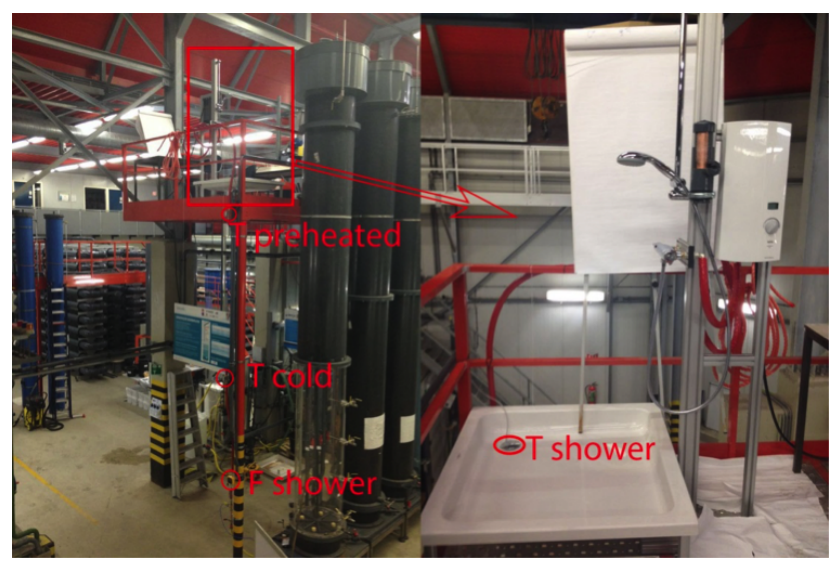

Figure 3. Experimental setup of the laboratory configuration.

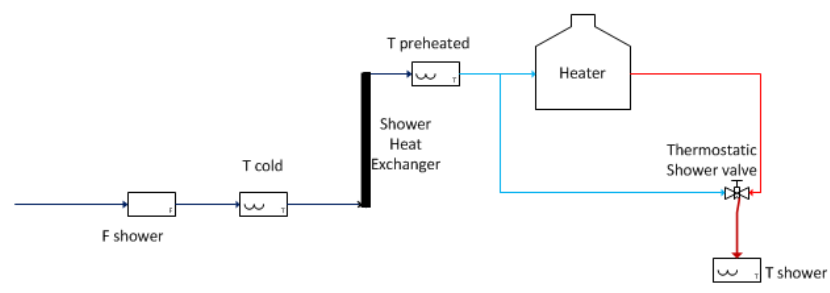

Figure 4. Flow diagram of the laboratory configuration ( $\mathrm{F}$ is flow meter, $\mathrm{T}$ is temperature sensor).

The configuration of the system includes three temperature sensors (SIEMENS QAD2012) and one flow meter (Kamstrup Multical $\left.{ }^{\circledR} 62\right)$. Figure 3 shows the experimental setup in the laboratory while Fig. 4 shows the flow diagram. The shower flow diagram of the laboratory configuration is the same as that of Uilenstede. The black line represents the cold water, which goes to the shower heat exchanger. The blue line represents the preheated water that goes to both the heater and the thermostatic valve. The red line is the heated water from the heater, and the dark red line indicates the used shower water that goes to the drain (temperature measured by $\mathrm{T}$ shower).

\subsubsection{Experiments}

In the laboratory, two experiments were carried out. The experimental conditions are summarized in Tables 1 and 2 .

In experiment 1 , a high shower temperature $\left(38^{\circ} \mathrm{C}\right)$ and two flow rates ( 5.4 and $6.5 \mathrm{~L} \mathrm{~min}^{-1}$, respectively) were applied to simulate the efficiency of the shower heat exchanger under winter conditions. There were six shower turns in one test, i.e., shower turn 1, 2, 3, 4, 5, and 6. Each shower turn lasted for $30 \mathrm{~min}$. The time interval between each shower turn increased from 10 to $20,30,60$, and then to $120 \mathrm{~min}$. Six tests (36 shower turns in total, 18 for winter conditions and 18 for summer conditions) were conducted to take average energy recovery efficiency for each flow rate. 
Table 1. Summary of experiments.

\begin{tabular}{lrr}
\hline & EXP1 & EXP2 \\
\hline Interval between showers (min) & $10,20,30,60,120$ & 15 \\
Number of tests & 6 & 2 \\
Shower durations (min) & 30 & 30 \\
Flow rates $\left(\mathrm{L} \mathrm{min}^{-1}\right)$ & $5.4,6.5$ & $5.2,6.8$ \\
Shower temperature $\left({ }^{\circ} \mathrm{C}\right)^{*}$ & 38 & 33 \\
Cold water temperature $\left({ }^{\circ} \mathrm{C}\right)$ & 10 & 20 \\
\hline
\end{tabular}

* Shower temperature is the temperature measured near the drain.

Table 2. Shower schedule per test.

\begin{tabular}{cc|cc}
\hline \multicolumn{2}{c|}{ EXP 1 } & \multicolumn{2}{c}{ EXP 2 } \\
\hline Time & Showers & Time & Showers \\
\hline $9: 00-9: 30$ & 1 & $9: 00-9: 30$ & 1 \\
$9: 40-10: 10$ & 2 & & \\
$10: 30-11: 00$ & 3 & $9: 45-10: 15$ & 2 \\
$11: 30-12: 00$ & 4 & & \\
$13: 00-13: 30$ & 5 & $10: 30-11: 00$ & 3 \\
$15: 30-16: 00$ & 6 & & \\
\hline
\end{tabular}

In experiment 2 , a lower shower temperature $\left(33^{\circ} \mathrm{C}\right)$ and a higher incoming water temperature $\left(20^{\circ} \mathrm{C}\right)$ were applied. These two temperatures were applied to create a smaller temperature difference between the cold water and shower water, in order to simulate the efficiency under summer conditions. Two flow rates of 5.2 and $6.8 \mathrm{~L} \mathrm{~min}^{-1}$ were compared in this experiment. Two tests were performed with three shower turns each, to get average energy recovery efficiency for each flow rate; 15 min time intervals were applied between each shower.

The shower turn durations, temperatures, and flow rates, which were applied in the two experiments, were determined based on the monitoring results and manual measurements in Uilenstede. In the experiments, room temperature and humidity were not registered.

\subsubsection{Analysis methods}

The energy and efficiency calculations are based on a standard method (NEN 7120+C2:2012, 2012).

$$
\begin{aligned}
Q_{\text {recovered }}= & \Sigma\left\{q_{\text {cold }} \times \rho\left(T_{\text {cold }}\right)\right. \\
& \left.\times\left[h\left(T_{\text {preheated }}\right)-h\left(T_{\text {cold }}\right)\right] \times \mathrm{d} t\right\}, \\
Q_{\text {waste }}= & \Sigma\left\{q_{\text {shower }} \times \rho\left(T_{\text {shower }}\right)\right. \\
& \left.\times\left[h\left(T_{\text {shower }}\right)-h\left(T_{\text {cold }}\right)\right] \times \mathrm{d} t\right\}, \\
\eta_{\text {recover }}= & \frac{Q_{\text {recovered }}}{Q_{\text {waste }}},
\end{aligned}
$$

where $Q_{\text {waste }}$ is the total energy in used shower water in kilojoule, $Q_{\text {recovered }}$ is the energy recovered by the shower heat exchanger in kilojoule, $q_{\text {cold }}$ is the drinking water flow rate through the shower heat exchanger in $\left[\mathrm{m}^{3} \mathrm{~s}^{-1}\right]$, and $q_{\text {shower }}$ is the shower water flow rate (should be the same as $q_{\text {cold }}$ in our laboratory case) through the shower heat exchanger in $\left[\mathrm{m}^{3} \mathrm{~s}^{-1}\right] . \rho(T)$ and $h(T)$ are the specific density and enthalpy of the water, as functions of the temperature according to

$$
\begin{aligned}
\rho(T)= & 999.9649+0.0264672 \times T-0.0061549 \times T^{2} \\
& +1.775 \times 10^{-5} \times T^{3} \text { in }\left[\mathrm{kJ} \mathrm{kg}^{-1}\right], \\
h(T)= & 0.167853+4.18587 \times T-0.000146789 \times T^{2} \\
& +9.38153 \times 10^{-7} \times T^{3}+8.36764 \times 10^{-9} \\
& \times T^{4} \text { in }\left[\mathrm{kJ} \mathrm{kg}^{-1}\right],
\end{aligned}
$$

$\eta_{\text {recover }}$ is the energy recovery efficiency [\%].

\subsection{Greenhouse gas emissions}

With the energy saved per shower calculated by Eq. (1), greenhouse gas emissions have been calculated with the factors and other parameters (from Waternet) from Table 3.

\subsection{Payback period}

The energy saved per shower was calculated by the Eq. (1), both in terms of electricity and natural gas. Based on this calculation and the other parameters presented in Table 4, the payback period calculation can be expressed as in Eq. (6).

Payback period $=\frac{\text { Cost }_{\text {exhchanger }}+\text { Cost }_{\text {labor }}}{\text { Energy saving } \times \text { Energy price }}$

\section{Results and discussion}

\subsection{Energy recovery efficiency}

With different types of heaters and fluctuations in drinking water temperature, there might be some minor variations in the time needed to stabilize the system. In general, it takes about $90 \mathrm{~s}$ to reach $90 \%$ (summer) to $99 \%$ (winter) of the final shower water temperature and preheated water temperature. In the Dutch Standard Method (NEN 7120+C2:2012), the calculation of energy recovery efficiency starts after the system becomes stable. But in this way, the energy saved during the warm-up period is excluded. The data in this study (Table 5) were collected from the beginning of the shower turn; therefore, the whole shower turn period was included. This approach describes the performance of the shower heat exchanger in a more realistic manner.

\subsubsection{Impact of flow rates, shower turn durations, water temperature differences, and shower turn intervals}

In winter conditions (Fig. 5a), the average energy recovery efficiency of a $5.4 \mathrm{~L} \mathrm{~min}^{-1}$ flow rate is in the range 
Table 3. Conversion factors and parameters used for $\mathrm{CO}_{2}$-equivalents calculation.

\begin{tabular}{lll}
\hline Parameter & Value & Unit \\
\hline $\mathrm{CO}_{2}$-eq conversion factor 1 & $1.63 \times 10^{-10}$ & ${\mathrm{kton} \mathrm{CO}_{2} \text {-eq kJ }}^{-1}$ electricity \\
$\mathrm{CO}_{2}$-eq conversion factor 2 & $1.8 \times 10^{-6}$ & ${\mathrm{kton} \mathrm{CO}_{2} \text {-eq Nm}}^{-3}$ gas \\
Population in Amsterdam & 800000 & - \\
Number of apartments in Amsterdam & 412000 & - \\
Natural gas consumption per household & 1600 & $\mathrm{Nm}^{3}$ \\
Electricity consumption per household & 1800 & $\mathrm{kWh}^{3}$ \\
$\mathrm{Nm}^{3}$ gas conversion to kWh & $8.76 \times 10^{-3}$ & $\mathrm{kWh} \mathrm{Nm}^{-3}$ \\
\hline
\end{tabular}

Table 4. Assumptions and information for payback period calculations.

\begin{tabular}{|c|c|c|c|c|}
\hline \multicolumn{5}{|c|}{ Assumption } \\
\hline \multirow[b]{2}{*}{ Type of house } & \multirow[b]{2}{*}{ Occupant } & \multirow[b]{2}{*}{ Showers per day } & \multicolumn{2}{|c|}{ Annual energy saving* } \\
\hline & & & $\begin{array}{r}\text { Electricity } \\
\left(\mathrm{kWh} \mathrm{yr}^{-1}\right)\end{array}$ & $\begin{array}{l}\text { Natural gas } \\
\left(\mathrm{Nm}^{3} \mathrm{yr}^{-1}\right)\end{array}$ \\
\hline Single-student apartments & 1 & 1 & 316.1 & 36 \\
\hline Normal household in Amsterdam & 2 & 2 & 632.2 & 72 \\
\hline Normal household in the Netherlands & 4 & 4 & 1264.4 & 144 \\
\hline \multicolumn{5}{|c|}{ Information } \\
\hline & $\begin{array}{l}\text { Shower heat exchanger } \\
\quad(\text { EUR unit }\end{array}$ & $\begin{array}{c}\text { Labor } \\
\left(\text { EUR unit }^{-1}\right)\end{array}$ & $\begin{array}{r}\text { Electricity } \\
\left(E U R \mathrm{kWh}^{-1}\right)\end{array}$ & $\begin{array}{l}\text { Natural gas } \\
\left(\text { EUR m }^{-3}\right)\end{array}$ \\
\hline Cost & 390 & 100 & 0.23 & 0.55 \\
\hline Reference & DSS & Uilenstede & & \\
\hline
\end{tabular}

* Calculated by Eq. (1).

of $64-64.5 \%$. When showering with a higher flow rate $\left(6.5 \mathrm{~L} \mathrm{~min}^{-1}\right)$, the average energy recovery efficiency was around $61.5-62 \%$. The recovery efficiency under the flow rate of $5.4 \mathrm{~L} \mathrm{~min}^{-1}$ was $2.5-3.0 \%$ higher than the flow rate of $6.5 \mathrm{~L} \mathrm{~min}^{-1}$. The efficiency gradually increased with the shower turn durations, but only within $0.5 \%$, which means that the efficiency of the shower heat exchanger was roughly stable against shower duration in winter. Taking a longer shower turn does not result in higher energy recovery efficiency.

In summer conditions (Fig. 5b), the cold water temperature in practice can exceed $20^{\circ} \mathrm{C}$; thus, the temperature difference between shower water and cold water was only $13{ }^{\circ} \mathrm{C}$ (in winter conditions it could be $28^{\circ} \mathrm{C}$ ). In this situation, a flow rate of $5.2 \mathrm{~L} \mathrm{~min}^{-1}$, which was used for the first three showers, resulted in an energy recovery efficiency of 61$62 \%$, and a flow rate of $6.8 \mathrm{~L} \mathrm{~min}^{-1}$, which was used for the last three showers, resulted in an energy recovery efficiency of 57-58\%. In all, $4 \%$ higher recovery efficiency was found when showering with the lower flow rate of $5.2 \mathrm{~L} \mathrm{~min}^{-1}$. This was similar to the findings in winter conditions.

Considering the shower turn duration, at flow rate of 5.2 $\mathrm{L} \mathrm{min}^{-1}$, the average efficiency for $8 \mathrm{~min}$ shower turns was $61.0 \%$, and $62.4 \%$ for 30 min showers; thus, a $1.4 \%$ increase was achieved. In winter conditions, the increase was limited to $0.5 \%$. When showering at $6.8 \mathrm{~L} \mathrm{~min}^{-1}$, the same phenomenon was observed: an extension from 8 min shower turns to 30 min shower turns in summer conditions resulted in an efficiency increase of $1 \%$, while in winter an increase of only $0.5 \%$ was observed. In summer conditions, the energy recovery efficiency increased with shower turn durations more significantly than in winter conditions.

Temperature differences between cold drinking water and shower water were smaller in summer conditions, which resulted in a 2-3\% lower (overall) efficiency.

Figure 6 shows six consecutive shower turns with increasing time intervals between the shower turns $(10,20,30,60$, and $120 \mathrm{~min}$ ), both for a flow rate of 5.4 and $6.5 \mathrm{~L} \mathrm{~min}^{-1}$. The time intervals between the showers affected the efficiencies. For instance, for $8 \mathrm{~min}$ shower turns, the recovery efficiency of shower turn 2 (which was taken 10 min after shower turn 1) was 0.5 and $1.0 \%$ higher than shower turn 6 (which was taken $120 \mathrm{~min}$ after shower turn 5), namely, by taking two showers with a shorter time interval, more energy could be saved. But this effect was significant only for shorter shower 

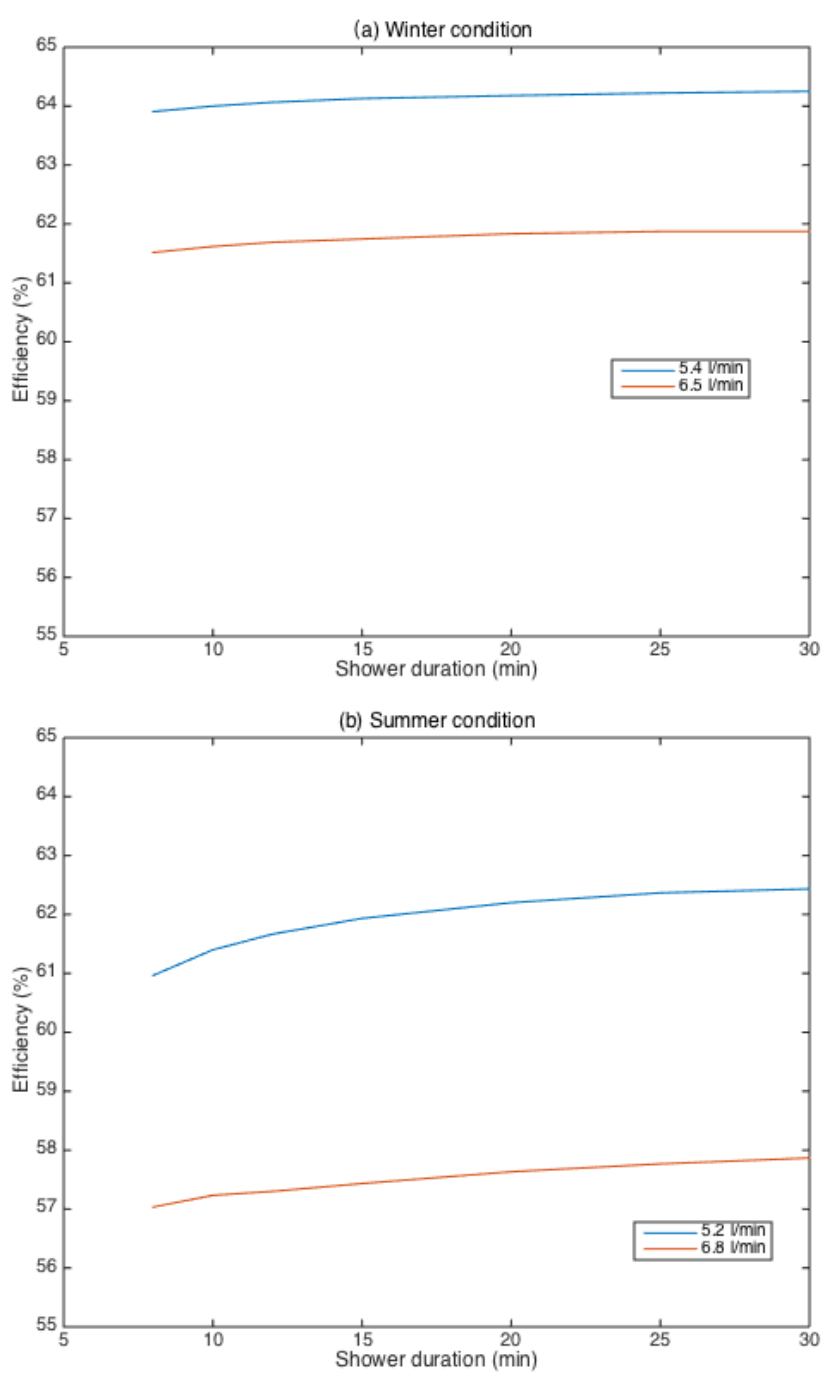

Figure 5. Energy recovery efficiencies versus impact parameters.

turns ( $<15 \mathrm{~min}$ ), and it was negligible for long shower turns exceeding $20 \mathrm{~min}$.

\subsubsection{Project Uilenstede}

Due to technical problems with the monitoring system, only data from one room (B0218, vertical WTW-unit) were valid in this phase. Records of four showers were found in Room B0218 (December, 2014), and an average energy recovery efficiency of $57 \%$ was calculated.

In this student house, the shower energy recovery efficiency was $4 \%$ lower than the laboratory winter conditions. The reasons for this might be (1) a smaller temperature difference or (2) a more fluctuated flow rate.

First, the cold water temperature inside the building was higher than the average drinking water temperature: it was $14.5^{\circ} \mathrm{C}$ in September and $12.5^{\circ} \mathrm{C}$ in December, while the average water temperature in the laboratory was $11^{\circ} \mathrm{C}$. There-
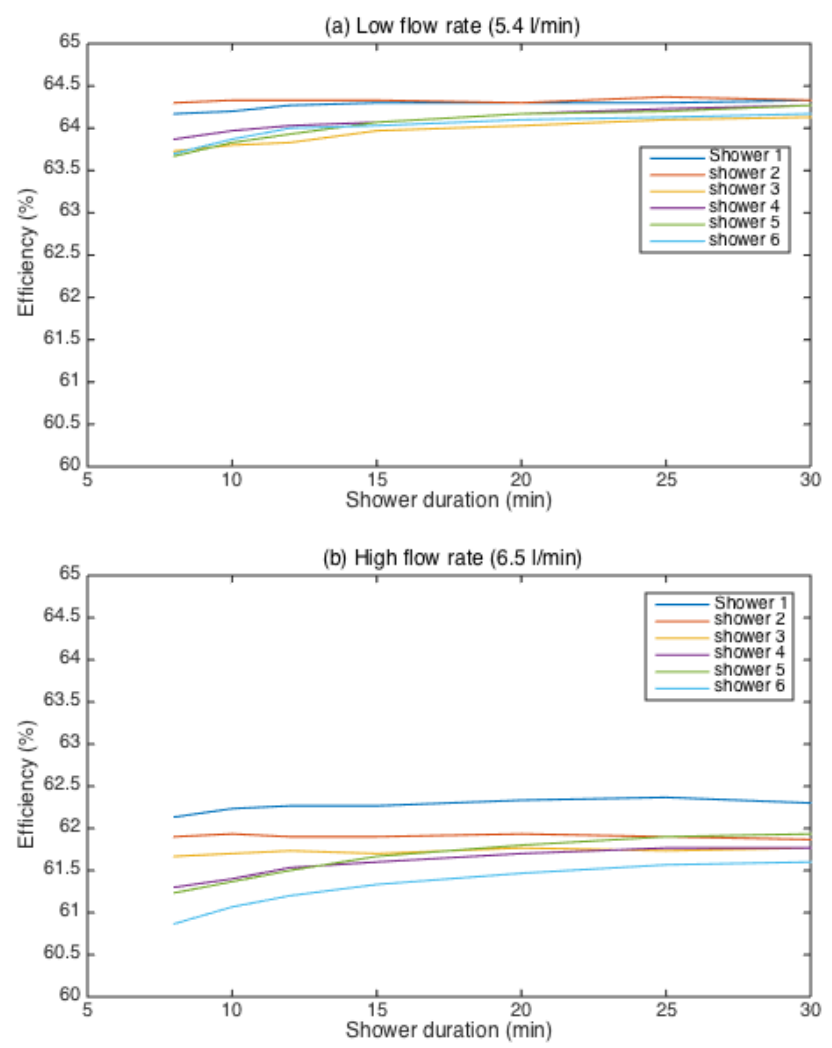

Figure 6. Energy recovery efficiency of each shower (average of three tests) in EXP 1.

fore, taking into account the shower water temperature between 34.5 and $37.5^{\circ} \mathrm{C}$, the temperature difference can be 2- $6{ }^{\circ} \mathrm{C}$ smaller.

Second, the water flow on a higher floor (i.e., second and third) tends to fluctuate more than on the ground floor. This was observed in both the monitoring results and manual measurements in the student's apartments.

The first cause was proven to be valid by the results of experiment 2 , but, unfortunately, due to the difficulty in controlling the flow rate in the laboratory, the second cause has not been tested. Additionally, the room temperature and humidity might have also had an impact on recovery efficiency; these data have still not been collected.

\subsection{Energy savings and $\mathrm{CO}_{2}$ reduction}

The average electricity and gas consumption in households is about $1800 \mathrm{kWh} \mathrm{yr}^{-1}$ and $1600 \mathrm{Nm}^{3} \mathrm{yr}^{-1}$ in Amsterdam (in 2012), and the total energy consumption equals 1770 kton $\mathrm{CO}_{2}$ emission (Table 3 ).

Assuming people take a 10 min showers each day with a water saving shower valve (about $5 \mathrm{~L} \mathrm{~min}^{-1}$ ), $0.4 \mathrm{kWh}$ (in summer) and $1.1 \mathrm{kWh}$ (in winter) per shower turn can be saved with a shower heat exchanger (calculated by Eq. 1). Under a maximum scenario, with 412000 apartments and a 
Table 5. Comparison of energy efficiencies.

\begin{tabular}{lrrrrrr}
\hline & DSS* & \multicolumn{3}{c}{ Lab } & Uilenstede \\
\cline { 3 - 5 } & & \multicolumn{2}{c}{ Winter } & \multicolumn{2}{c}{ Summer } \\
\hline Shower temperature $\left({ }^{\circ} \mathrm{C}\right)$ & 40 & \multicolumn{2}{c}{38} & \multicolumn{2}{c}{33} & 34.5 \\
Cold water temperature $\left({ }^{\circ} \mathrm{C}\right)$ & 10 & $9-10$ & $19-20$ & 12.5 \\
Flow rate $\left(\mathrm{L} \mathrm{min}^{-1}\right)$ & 5.8 & 5.4 & 6.5 & 5.2 & 6.8 & 6.4 \\
Efficiency $(\%)$ & 62.7 & 64 & 61 & 62 & 58 & 57 \\
\hline
\end{tabular}

* Dutch Solar Systems (2015)

Table 6. Estimation of energy recovery and $\mathrm{CO}_{2}$ emission reduction.

\begin{tabular}{lcr}
\hline Annual energy saved by shower heat exchanger & $\mathrm{kWh}$ & 260000000 \\
Electricity consumed in households & $\mathrm{kWh}$ & 740000000 \\
Gas consumed in households & $\mathrm{kWh}$ & 5800000000 \\
Annual total consumption & $\mathrm{kWh}$ & 6540000000 \\
\hline Saving compared to electricity & $\%$ & 35.0 \\
Saving compared to gas & $\%$ & 4.5 \\
Saving compared to total energy & $\%$ & 4.0 \\
\hline $\mathrm{CO}_{2}$ reduction & kton & 54 \\
\hline
\end{tabular}

population density of 2 per dwelling in Amsterdam, the energy that can be recovered is around $900000 \mathrm{kWh}^{-1} \mathrm{yy}^{-1}$ in winter and $300000 \mathrm{kWh} \mathrm{day}^{-1}$ in summer. The energy recovered in 1 year is approximate 260 million kWh (122 days are counted as summer with average drinking water temperature above $20^{\circ} \mathrm{C} ; 243$ days as winter). This is $4.0 \%$ of the total households electricity and gas consumption, which equals 6540 million kWh (Table 6).

In the Netherlands, shower water is mainly heated by gas. With a shower heat exchanger in every house in Amsterdam, a $4.5 \%$ reduction in gas consumption can be achieved per year, which is equivalent to saving about 30 million $\mathrm{Nm}^{3} \mathrm{yr}^{-1}$ gases, or a reduction of $54 \mathrm{kton} \mathrm{CO}_{2}$. With re-

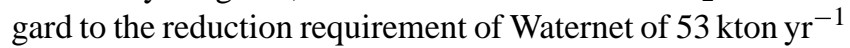
(van der Hoek, 2012b), this would be a significant achievement.

It is difficult to forecast to what extend this maximum scenario will be realized, as it also depends on incentives and thus the policy of the city of Amsterdam. In addition, on the long term the efficiency of shower heat exchangers may decrease due to fouling and corrosion. Hence, the estimation might be too optimistic. However, it shows the benefits of installing shower heat exchangers and it stresses the importance of promoting the installation of the shower heat exchangers.

\subsection{Payback period}

A shower heat exchanger costs EUR 390 and the installation was about EUR 100 in Uilenstede, which brings the total costs to about EUR 500. With an average natural gas price of EUR $0.55 \mathrm{Nm}^{-3}$, and the annual gases saving per capita (about $36 \mathrm{Nm}^{3}$ ), the payback period for single-student apartments is around 13 years.

The payback period becomes shorter when the number of occupants increases. For example, in a four-person residence house, the payback period could be less than 4 years. Although the installation cost might be underestimated (no pipelines have to be changed in the new student apartments), the annual saving (EUR $152 \mathrm{yr}^{-1}$ ) was quite close to the DSS estimation (EUR $126 \mathrm{yr}^{-1}$ for normal Dutch households with four people). Concerning the apartments using electricity for water heating (electricity price EUR $0.23 \mathrm{kWh}^{-1}$ ), the payback period can be as short as 2 years. If taking into account a higher installation fee, the estimation of payback period is close to the estimation (4-25 years) found by Mol (2013).

The aging of the material and the fouling of the inner pipes could lead to a deterioration of the recovery efficiency, which might also increase the payback period. This effect was not examined in these short-term observations, but it will be studied in the next stage long-term observations in the Uilenstede project site.

\section{Conclusions}

The energy recovery efficiency observed in this study (57$64 \%$ observed in the lab and $57 \%$ observed in Uilenstede) is quite close to the claimed efficiency (56-62.7\% for vertical shower heat exchanger). The performance of the shower heat exchanger is relatively stable for different shower turn durations, shower turn intervals, and seasonal impacts, while the flow rate of the shower was shown to have a more significant influence: a lower flow rate resulted in a higher energy recovery efficiency. Therefore, combining shower heat exchangers with water saving shower valves is recommended.

With a shower heat exchanger, the energy recovered by 412000 households in Amsterdam is about 260 million $\mathrm{kWh} \mathrm{yr}^{-1}$, which equals a reduced greenhouse gas emission of $54 \mathrm{kton} \mathrm{CO}_{2} \mathrm{yr}^{-1}$. The potential of shower heat ex- 
changers is promising, and once implemented they could provide a large contribution to the $\mathrm{CO}_{2}$ reduction target of Waternet in 2020.

Based on the costs of the Uilenstede project, the average payback period in single-student apartments that uses gas for heating shower water is about 13 years, and about 7 years when electricity is used. The installation cost might be higher for older apartments, but it can be compensated by having more occupants using the same bathroom.

Edited by: A. Mittal

\section{References}

City of Amsterdam: Amsterdam: a Different Energy - 2040 Energy Strategy, Report City of Amsterdam, Klimaatbureau, Amsterdam, the Netherlands, 2009.

Dutch Solar Systems: DSS shower drain water heat recovery unit, Enschede, the Netherlands, available at: http://www.dutchsolarsystems.com/douche_wtw/downloads/ 4029152-folder\%20DSS-douchepijp-ENGELS-LR.pdf, last access: 3 March, 2015.

Hofman, J., Hofman-Caris, R., Nederlof, M., Frins, J., and Van Loosdrecht, M.: Water and energy as inseparable twins for sustainable solutions, Water Sci. Technol., 63, 88-92, 2011.

IPCC: Summary for policymakers, in: Climate Change 2013: The Physical Science Basis. Contribution of Working Group I to the Fifth Assessment Report of the Intergovernmental Panel on Climate Change, edited by: Stocker, T. F., Qin, D., Plattner, G. K., Tignor, M., Allen, S. K., Boschung, J., Nauels, A., Xia, Y., Bex, V., and Midgley, P. M., Cambridge University Press, Cambridge, UK and New York, NY, USA, 4-29, http://www.ipcc.ch/pdf/assessment-report/ar5/wg1/ WG1AR5_SPM_FINAL.pdf, 2013.
Liu, L., Fu, L., and Jiang, Y.: Application of an exhaust heat recovery system for domestic hot water, Energy, 35, 1476-1481, 2010.

Mol, S.: Evaluation of shower heat exchanger as a means for $\mathrm{CO}_{2}$ reduction in the water cycle, Report Waternet, Amsterdam, the Netherlands, 2013.

NEN 7120+C2:2012: Energieprestatie van gebouwen - Bepalingsmethode (Dutch Standard "Energy performance of buildings"), the Netherlands Standardisation Institute, Delft, the Netherlands, 2012.

van der Hoek, J. P.: Climate change mitigation by recovery of energy from the water cycle: a new challenge for water management, Water Sci. Technol., 65, 135-141, 2012a.

Van der Hoek, J. P.: Towards a climate neutral water cycle, Journal of Water and Climate Change, 3, 163-170, 2012b.

Van Thiel, L.: Watergebruik Thuis 2013 (Water Use at Home 2013), Report G5707 TNS Nipo/Vewin, 17 February 2014, Amsterdam, the Netherlands, 2014.

Wong, L. T., Mui, K. W., and Guan, Y.: Shower water heat recovery in high-rise residential buildings of Hong Kong, Appl. Energy, 87, 703-709, 2010. 